\title{
Buckling analysis of Composite Plate with Central Elliptical Cut out
}

\author{
Sa'el Saleh Al-Jameel \\ Assistant Lecturer \\ Dr. Rafi K. Albazzaz \\ Mech. Eng. Dept. \\ Assistant Professor \\ Mosul University
}

\begin{abstract}
In this study, the multilayer composite plates consist from aluminum, brass, and steel with unsaturated polyester Resin (UPE) as a core material. The plates having a central circular, elliptical holes. The buckling parameters such as aspect ratios and different hole orientation angles have been analyzed numerically.These parameters have been applied at different layers of materials both metallic and non metallic. Analyses were carried out using finite element method (FEM) through the application of special numerical program written in APDL by ANSYS software. Result shows that the buckling load were highly dependent on the type of composite material, and the buckling load increased by increasing elliptical hole orientation angle. Increasing of major and minor diameters of elliptical holes with plate $b / w$ ratios were decrease the buckling load for the multilayer composite plate.
\end{abstract}

Key words: Buckling behavior, Composite material, Elliptical hole, FEM

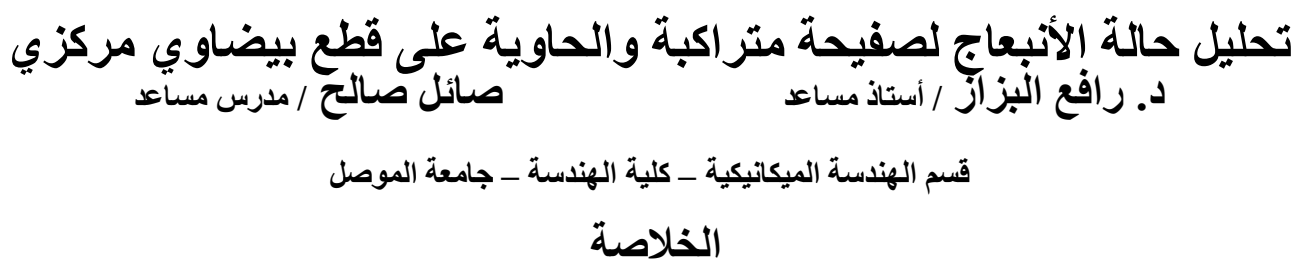

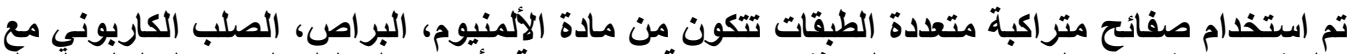

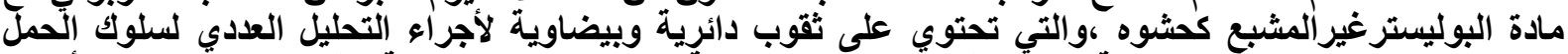

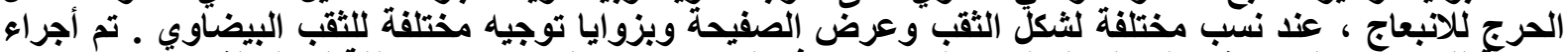

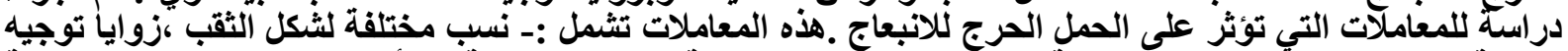

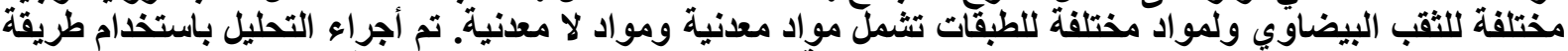

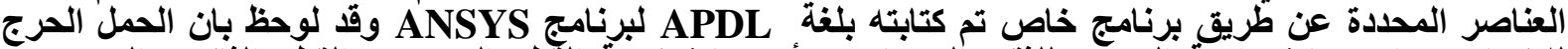

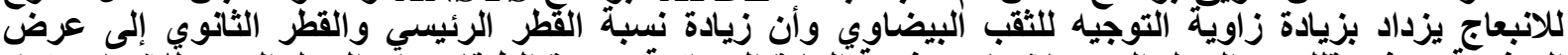

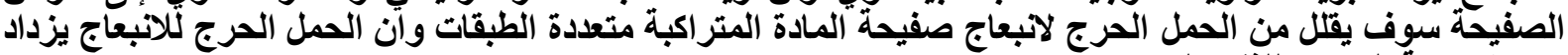
بزيادة زاوية التوجيه للثقب البيضاوي.

كلمات مفتاحية : سلوك الانبعاج ، مادة متراكبة ، ثقب بيضاوي ،طريقة العناصر المحددة

Received: 10 - 1 - 2013

Accepted: 9 - 7 - 2013 


\section{Introduction}

Composite structures and plates are widely used in many applications in our lives and their usage were growing rapidly especially in the aerospace industry and many other important fields which need a high strength -to-weight ratios. The presence of cutouts in the composite plates full fills these needs by saving weight of the material. Therefore the study of the buckling loads behavior of the composite material containing holes are very important for the designers and engineers.

Many researchers studied the effect of cut out on buckling loads in plates.

Aydin M. komur et al. [1] analyzed the buckling load of woven-glass-polyester laminated composite plate with circular/elliptical holes .By using the finite element method .They concluded that the magnitude of buckling loads are decreased by increasing the cutout shape ratios. Gansen. C, Dash P.K. [2] studied the effect of various cutout shapes (circular, square and elliptical) on the buckling load of a symmetrically composite plate. They found that there is a reduction of stress intensity and hence increasing buckling load when the location of cut out at the center of plate especially for higher aspect ratios.

Niranjan M. S. et al. [3] studied the behavior of a laminated composite skew plate with elliptical hole subjected to inner laminar stresses to transverse pressure loading using finite element method. They observed that the magnitude of the transverse deflection and in plane stresses is reduced at higher skew angles and for larger size of cutouts. Better results are obtained when the ellipse major diameter is parallel to the incline side of the skew plate. Rajendran S., Song D.Q. [4] studied the delamination buckling VICOTEX woven fabric carbon-epoxy composite panel using finite element technique. They found that the buckling loads were affected by delamination location in the laminates and when the delamination is very close to the surface it reduces the buckling load. Niranjan M. S. et al[5] studied the thermo elastic behavior of cross-ply laminated composite skew plate with variable orientation of elliptical cutouts subjected to pressure loading and under linearly varying temperature . They used the finite element method to find that the temperature loading and the orientation have a significant effect on the inter laminar normal stresses and minimized when orientation angle increased. Husam Al Qablan, et al [6] studied the effect of various parameters (cut out size, cutout location, fiber orientation angle and type of loading) on the buckling load of cross ply laminated plates with circular cutout. they found that buckling load is decreased as the cutout size increased, and the buckling load is highly effected by the location of the cutout where it take a larger value when the cutout location is in the middle of the plate.

Firas S. Jarrar, Naser S. Al-Huniti[7] studied the buckling behavior of laminated metal matrix composite(MMC) plate with a single and double central cutouts. They found that stronger buckling behavior in the case of a single cut out than that for multiple cutouts. Hani Aziz Ameen [8] investigated the buckling load experimentally and numerically for E-glass fiber reinforced polyester plastic composite materials with different cut out shapes( circle, square, rectangle), and he found a good agreement in the behavior of decreasing the buckling load with changing the shape of the cut out from square and rectangular to circular . Raed Hekmat Maty [9] studied the effects of holes geometry and shapes on the buckling characteristics of the plates with cutout. He found that the square plates with circular and elliptical cutouts decrease in buckling strengths as the cutout sizes were increased.

In this study the multilayer composite plate, were used. Square plate with side length (w) equal to $100 \mathrm{~mm}$ and total plate thickness equal to $4 \mathrm{~mm}$, consisting of three layers bonded each other .The first and the third are metallic layers plates with thickness $\left(t_{1} \& t_{3}\right)$ equal to 1 
$\mathrm{mm}$ for each layer, while the second layer is non metallic layer with thickness $\left(\mathrm{t}_{2}\right)$ equal to 2 $\mathrm{mm}$. The two upper and lower opposite sides are clamped and subjected to compressive load. The other two sides are free, having a central elliptical shape cutout.

The orientation angle of the elliptical shape cutout were varying from $\theta=0^{\circ}$ to $90^{\circ}$ with a step of $15^{\circ}$ and the aspect ratios of $(\mathrm{a} / \mathrm{w})$ and $(\mathrm{b} / \mathrm{w})$ were changing from 0.1 to 0.5 for each ratio as shown in Fig.(1) .

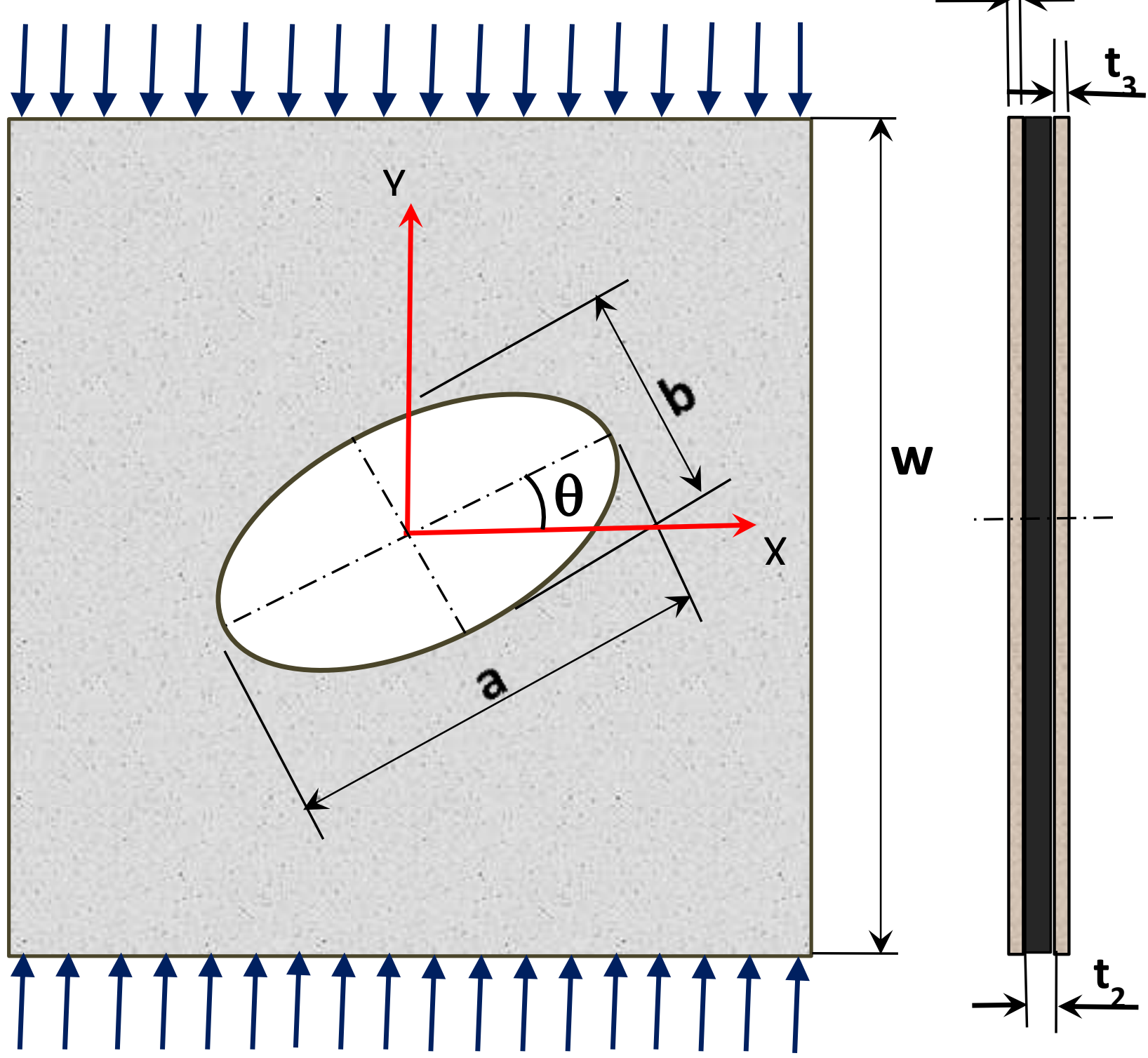

Fig. (1) The Multilayer composite plate and the coordinate system.

Different types of metals can be used for the $1^{\text {st }}$ and the $3^{\text {rd }}$ layers, the study concentrated on the types which are widely used and more economics, these types were: aluminum alloy, $\alpha$ Brass, and mild steel. The non metallic layer made from unsaturated polyester resin (UPE).Resulting three different types of multilayer composite plates(AL-UPE),( BrassUPE)and( Steel-UPE). Tables $(1,2,3)$ shows the chemical compositions of aluminum alloy, $\alpha$ 
Brass, and mild steel [10] , and table (4) shows the mechanical properties of the aluminum alloy, $\alpha$ Brass and mild steel used [10] and tables (5) show the mechanical properties for the unsaturated polyester resin (UPE)[11][12]. The evaluating of the critical buckling load were found using ANSYS 9 finite element analysis/method (FEM) code.

Table (1) Chemical composition of the aluminum plate [10].

\begin{tabular}{|c|c|c|c|c|c|c|c|c|c|}
\hline Material & $\begin{array}{l}\mathrm{Ni} \\
\%\end{array}$ & $\begin{array}{l}\mathrm{Ti} \\
\%\end{array}$ & $\begin{array}{l}\mathrm{Cr} \\
\%\end{array}$ & $\begin{array}{l}\mathrm{Zn} \\
\%\end{array}$ & $\underset{\%}{\mathrm{Mg}}$ & $\underset{\%}{M n}$ & $\mathrm{Cu}$ & $\begin{array}{l}\mathrm{Fe} \\
\%\end{array}$ & $\begin{array}{l}\text { Al } \\
\%\end{array}$ \\
\hline $\begin{array}{c}\text { Aluminum } \\
\text { alloy }\end{array}$ & 0.001 & 0.016 & 0.009 & 0.027 & 0.01 & 0.015 & 0.15 & 0.58 & Rem. \\
\hline
\end{tabular}

Table (2) Chemical composition of the Mild steel plate [10].

\begin{tabular}{|c|c|c|c|c|c|c|c|c|c|c|}
\hline Material & $\begin{array}{c}\text { Cu } \\
\text { \% }\end{array}$ & $\begin{array}{c}\text { Mo } \\
\text { \% }\end{array}$ & $\begin{array}{c}\text { Ni } \\
\text { \% }\end{array}$ & $\begin{array}{c}\text { Cr } \\
\text { \% }\end{array}$ & $\begin{array}{c}\text { S } \\
\text { \% }\end{array}$ & $\begin{array}{c}\text { P } \\
\text { \% }\end{array}$ & $\begin{array}{c}\text { Si } \\
\text { \% }\end{array}$ & $\begin{array}{c}\text { Mn } \\
\text { \% }\end{array}$ & $\begin{array}{c}\text { C } \\
\text { \% }\end{array}$ & $\begin{array}{c}\text { Fe } \\
\text { \% }\end{array}$ \\
\hline Mild Steel & $\mathbf{0 . 0 4}$ & $\mathbf{0 . 0 0 7}$ & $\mathbf{0 . 0 3}$ & $\mathbf{0 . 0 4}$ & $\mathbf{0 . 0 1 1}$ & $\mathbf{0 . 0 0 4}$ & $\mathbf{0 . 0 2 2}$ & $\mathbf{0 . 3 5}$ & $\mathbf{0 . 2 1}$ & Rem. \\
\hline
\end{tabular}

Table (3) Chemical composition of the Brass plate [10].

\begin{tabular}{|c|c|c|c|c|c|}
\hline Material & $\begin{array}{c}\text { Mn } \\
\boldsymbol{\%}\end{array}$ & $\begin{array}{c}\text { Pb } \\
\boldsymbol{\%}\end{array}$ & $\begin{array}{c}\text { Fe } \\
\boldsymbol{\%}\end{array}$ & $\begin{array}{c}\mathbf{Z n} \\
\boldsymbol{\%}\end{array}$ & $\begin{array}{c}\mathrm{Cu} \\
\boldsymbol{\%}\end{array}$ \\
\hline$\alpha$ Brass & $\mathbf{0 . 0 0 1}$ & $\mathbf{0 . 0 0 1}$ & $\mathbf{0 . 1 9}$ & $\mathbf{2 6 . 2}$ & Rem. \\
\hline
\end{tabular}

Table (4) Mechanical Properties of the used plates [10].

\begin{tabular}{|c|c|c|c|c|c|}
\hline Material & $\begin{array}{c}\text { Tensile } \\
\text { stress } \\
(\mathbf{M P a})\end{array}$ & $\begin{array}{c}\text { Percent } \\
\text { Elongation } \\
(\%)\end{array}$ & $\begin{array}{c}\text { Poisson's } \\
\text { Ratio }\end{array}$ & $\begin{array}{c}\text { Modulus of } \\
\text { Elasticity } \\
(\mathbf{G P a})\end{array}$ & $\begin{array}{c}\mathbf{0 . 2 \%} \text { Proof } \\
\text { Stress(MPa) }\end{array}$ \\
\hline Aluminum alloy & $\mathbf{1 7 8}$ & $\mathbf{9 . 2}$ & $\mathbf{0 . 3 3}$ & $\mathbf{7 0 . 1}$ & $\mathbf{8 0}$ \\
\hline Mild Steel & $\mathbf{5 7 0}$ & $\mathbf{2 7 . 6}$ & $\mathbf{0 . 3 2}$ & $\mathbf{2 0 0}$ & $\mathbf{4 3 0}$ \\
\hline$\alpha$ Brass & $\mathbf{5 4 0}$ & $\mathbf{3 5 . 5}$ & $\mathbf{0 . 3 4}$ & $\mathbf{1 0 4}$ & $\mathbf{4 0 0}$ \\
\hline
\end{tabular}

Table (5) Properties of the Unsaturated Polyester resin (UPE) [11][12].

\begin{tabular}{|c|c|c|c|c|c|c|}
\hline Name & $\begin{array}{c}\text { Density } \\
\left(\mathrm{gm} / \mathbf{c m}^{3}\right)\end{array}$ & $\begin{array}{c}\text { Specific } \\
\text { Heat } \\
(\mathrm{J} / \mathrm{Kg} . \mathbf{k})\end{array}$ & $\begin{array}{c}\text { Modulus of } \\
\text { Elasticity } \\
(\mathbf{G P a})\end{array}$ & $\begin{array}{c}\text { Percent } \\
\text { Elongation } \\
(\mathbf{E L \%})\end{array}$ & $\begin{array}{c}\text { Poisson's } \\
\text { Ratio }\end{array}$ & $\begin{array}{c}\text { Tensile } \\
\text { Strength } \\
(\mathbf{M P a})\end{array}$ \\
\hline Polyester resin & $\mathbf{1 . 2}$ & $\mathbf{7 1 0 - 9 2 0}$ & $\mathbf{2 . 0 6 - 4 . 1 1}$ & $<2.6$ & $\mathbf{0 . 3 7 - 0 . 3 9}$ & $\mathbf{4 1 . 4 - 8 9 . 7}$ \\
\hline
\end{tabular}

\section{Finite Element and Modeling Buckling analysis.}

In order to predict the buckling load of the multilayer composite plate structure ANSYS 9 finite element program was used. The ANSYS program employs two techniques to find the buckling load of a structure: nonlinear and Eigen value (or linear) techniques. Using the nonlinear technique, the model can include features such as initial imperfections, plastic behavior, gaps, and large-deflection response. For instance, an Eigen value buckling analysis of a column will match the classical Euler solution. However, imperfections and nonlinearities prevent most real-world structures from achieving their theoretical elastic buckling strength [13]. In this study the Eigen value technique was used. The static solution 
for the structure and the prebuckling stresses were found and after that the Eigen value problem is solved which have the following form [13]:

$$
\left([K]+\lambda_{i}[S]\right)\left\{\psi_{i}\right\}=\{0\}
$$

Where

$[\mathrm{K}]$ : stiffness matrix

$[\mathrm{S}]:$ stress stiffness matrix

$\lambda_{i}$ : ith Eigen value (used to multiply the loads which generated [S]

$\psi_{i}:$ ith eigenvector of displacements

"SHELL99"element was chosen for the modeling and mesh of the composite multilayer plate, this element is an 8node, 3-D shell element type, and has six degrees of freedom at each node: translations in the nodal $\mathrm{x}, \mathrm{y}$, and $\mathrm{z}$ directions and rotations about the nodal $\mathrm{x}$, $y$, and z-axes[13]. Fig.(2) represent the properties of this element [13].

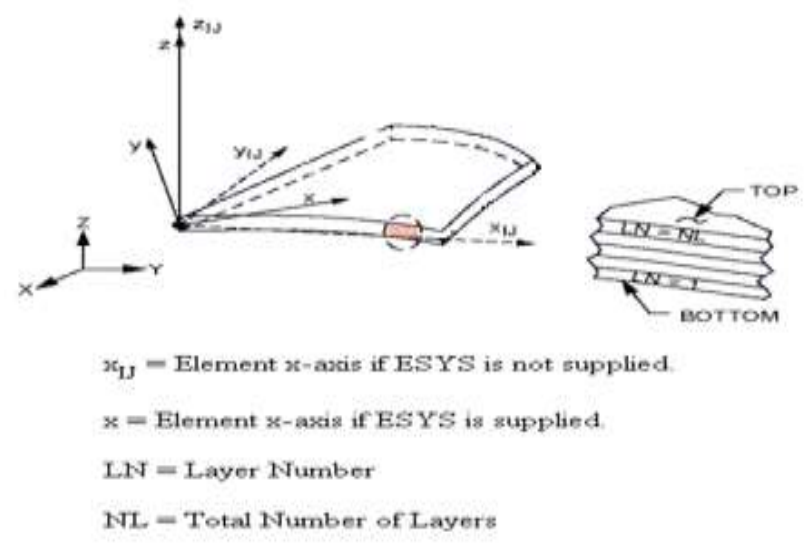

Fig. (2) ANSYS Element SHELL99 properties [13].

Fig. (3) Shows the meshed finite element model for multilayer composite plate with cut out at different elliptical orientation angle. A total number of 2400 elements has been found to produce finite element convergence.
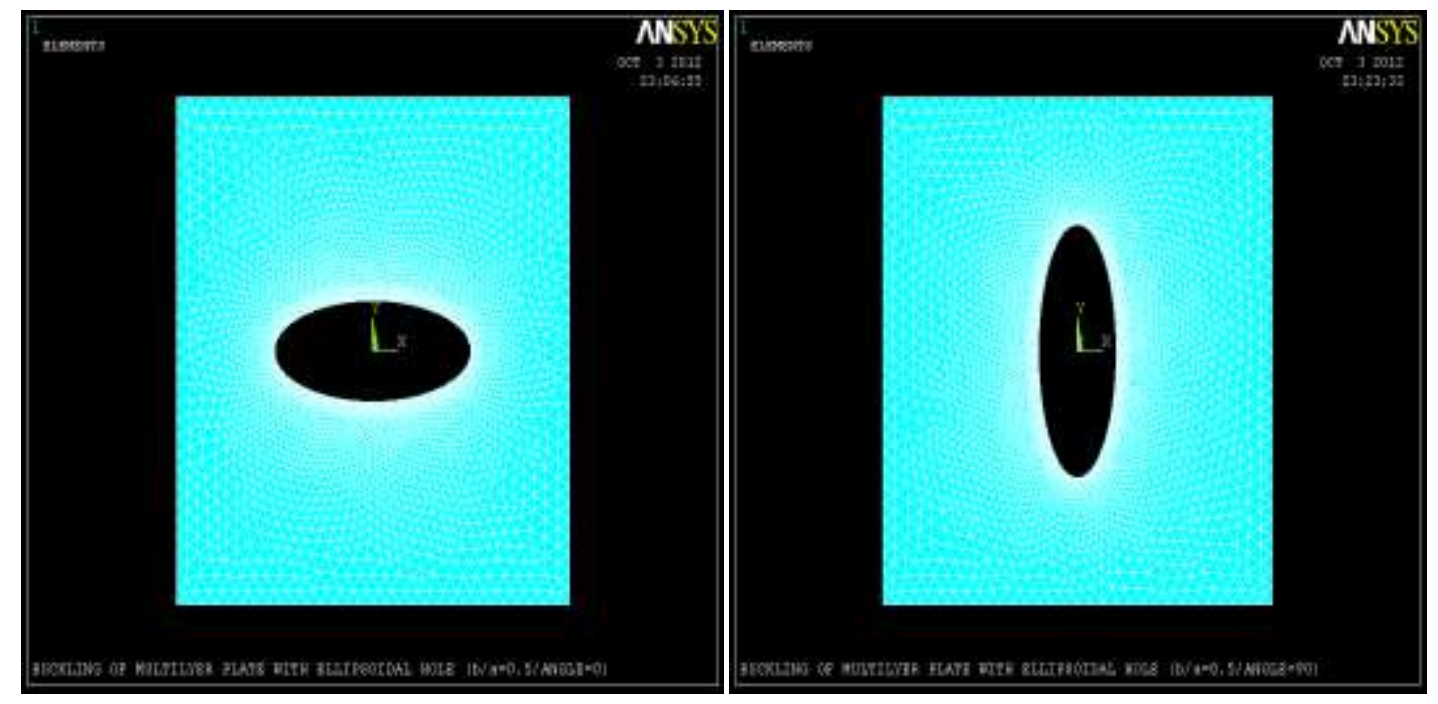

Fig. (3) ANSYS Meshed Finite element model for multilayer composite plate containing central cutout at different elliptical orientation angles. 
And before we begin the prediction the buckling load by the finite element method a check for the numerical solution had been done for the case of steel, Brass and Aluminum plates and having no cut out through it by using equations (1) and (2) [14]. Table (6) includes values of the buckling strength for the above plates calculated by the use of equation (1) and (2).

$\sigma_{c r}=\frac{K_{r} \pi^{2} D}{t W^{2}}$

$K_{r}=\left(\frac{m}{r}\right)^{2}+p+q\left(\frac{r}{m}\right)^{2}$

$D=\frac{E t^{3}}{\left[12\left(1-v^{2}\right)\right]}$

Where

E : Modulus of elasticity(Pa.)

$\mathrm{v}$ :Poisson's ratio

$\mathrm{m}$ : Number of halve waves of buckling

$\mathrm{P}$, q: rotational constraint factors

r: Aspect ratio

\section{Results and Discussion}

Figs. $(5,6)$ Shows that the buckling load increased when the elliptical hole orientation angle $\theta$ increased from $0^{\circ}$ to $90^{\circ}$, this is because the generated stresses in the direction of loads were low with uniformly distributed around the cutout holes. The generated stresses becomes high and not uniform around the cutout when $\theta=45^{\circ}$ and $\theta=0^{\circ}$ compared with $\theta=90^{\circ}$ as shown in Figs. $(7,8,9)$.The higher value of buckling loads have been observed for mild steel-UPE followed by Brass-UPE and Aluminum-UPE. Higher of the buckling load for the multilayer plates compared with single metal plates were noticed, the same Behavior were observed for the other ratios of $(\mathrm{a} / \mathrm{w}),(\mathrm{b} / \mathrm{w}$. Increasing of $(\mathrm{a} / \mathrm{w})$ and $(\mathrm{b} / \mathrm{w})$ ratios causes the decreasing of the value of the buckling loads as shown in Figs. $(10,11,12,13)$.

Figs. $(14,15,16)$ show the variation of buckling load with $(\mathrm{a} / \mathrm{w})$ ratio for the individual material of the plate $(\mathrm{b} / \mathrm{w}$ ratio $=0.5)$, observing that when $(\mathrm{a} / \mathrm{w})$ ratio $=0$ and $(\mathrm{a} / \mathrm{w})$ ratio $=0.5$, the multilayer composite plate have the same buckling load with respect to hole orientation angle, because when $(\mathrm{a} / \mathrm{w})$ ratio $=0$ the plate is blank, and when $(\mathrm{a} / \mathrm{w})$ ratio $=0.5$ and $(\mathrm{b} / \mathrm{w})=0.5$ the hole will be circle, therefore hole orientation angle have no effect on the Buckling load values, The same behavior was noticed for the variation of Buckling load with the $(b / w)$ ratio for the individual material (with $(\mathrm{a} / \mathrm{w})$ ratio $=0.5)$ as shown in Figs. $(17,18,19)$.

Table (6) Comparison of Theoretical and Numerical values of the Calculated buckling strength.

\begin{tabular}{|c|c|c|c|c|}
\hline No. & Material & $\begin{array}{c}\text { Numerical Value } \\
\text { of } \sigma_{\text {cr }}(\mathbf{M p a})\end{array}$ & $\begin{array}{c}\text { Theoretical Value } \\
\text { of } \sigma_{\text {cr }}(\mathbf{M p a})\end{array}$ & $\begin{array}{c}\text { Percent } \\
\text { Error } \%\end{array}$ \\
\hline 1 & Mild Steel & 77.845 & 78.182 & 0.431 \\
\hline 2 & $\alpha$ Brass & 57.165 & 56.857 & 0.541 \\
\hline 3 & Aluminum alloy & 49.551 & 49.752 & 0.404 \\
\hline
\end{tabular}




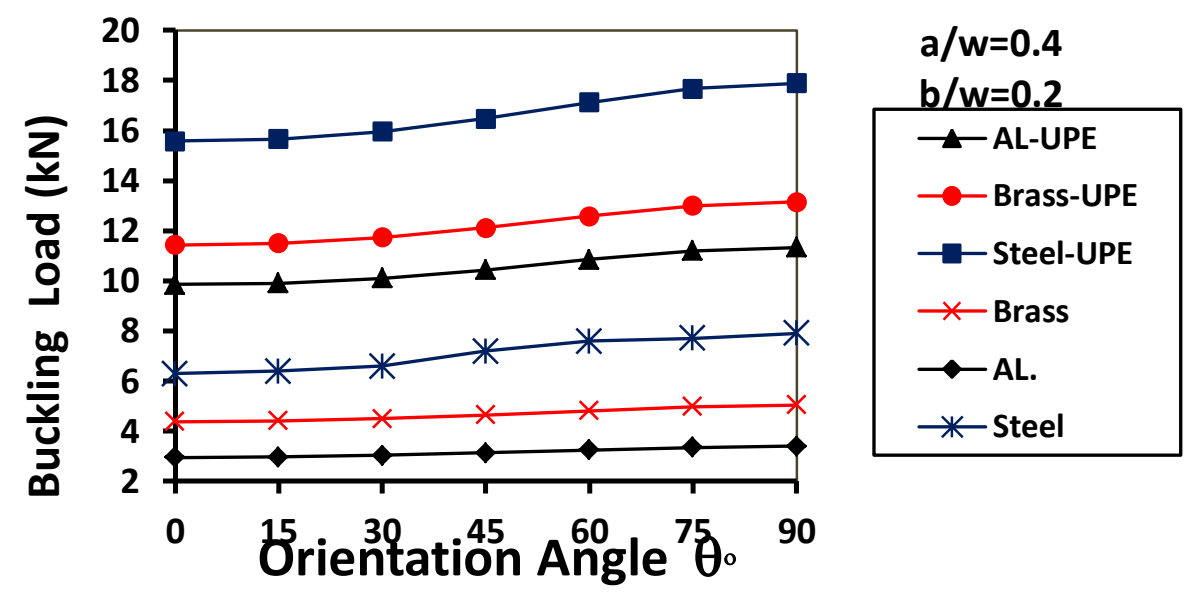

Fig. (5) Variation of buckling load with elliptical hole orientation angle for Ratios $(\mathrm{a} / \mathrm{w})=0.4$.

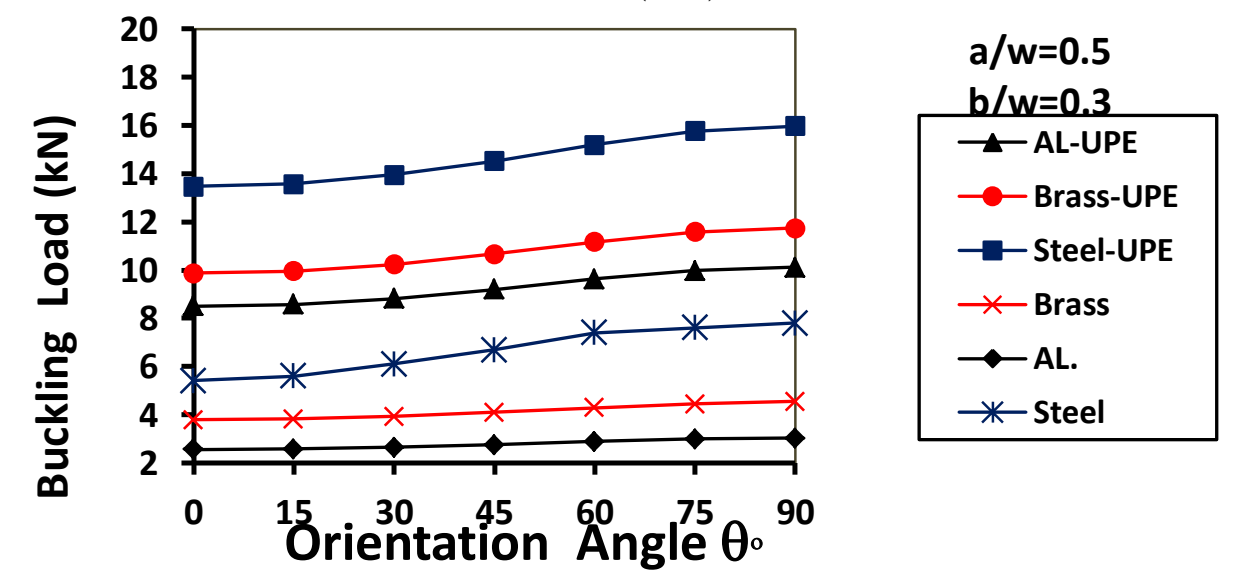

Fig. (6) Variation of buckling load with elliptical hole orientation angle: for Ratios $(\mathrm{a} / \mathrm{w})=0.5$

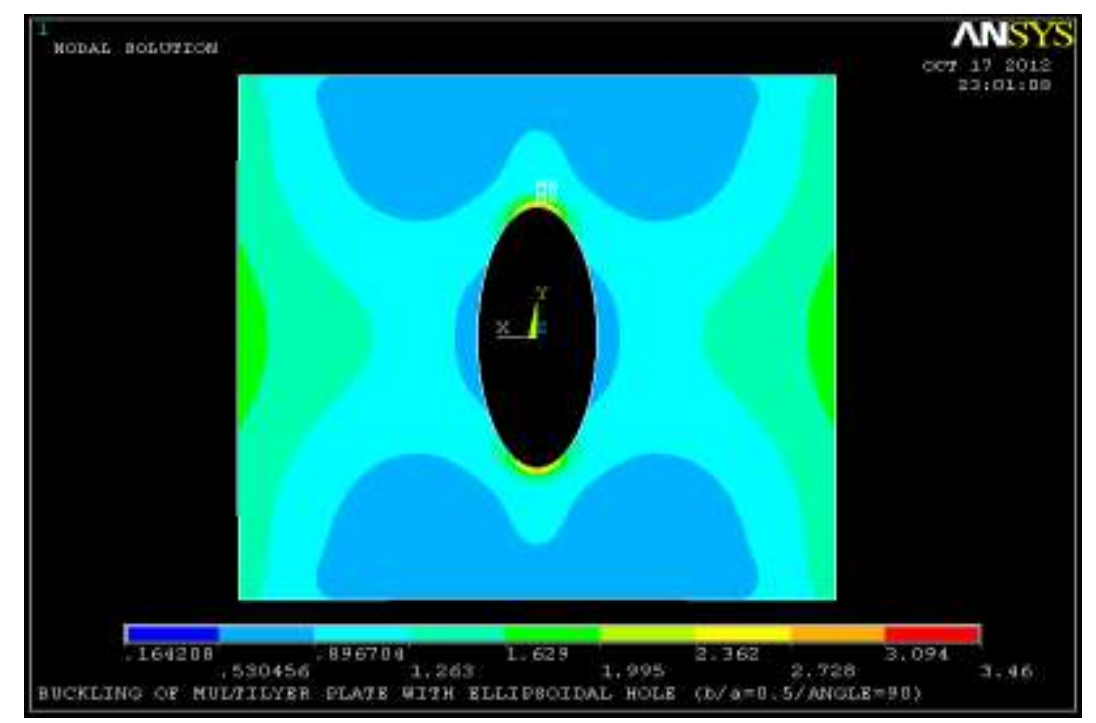

Fig. (7) ANSYS contour plot of stress distribution for multilayer plate for $\theta=90^{\circ}$. 


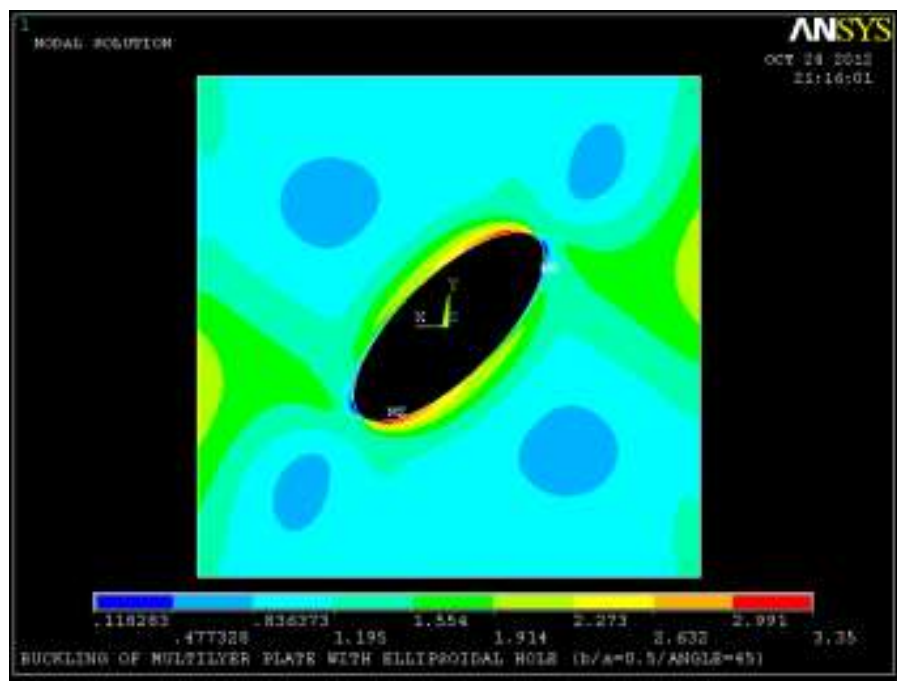

Fig. (8) ANSYS contour plot of stress distribution for multilayer plate for $\theta=45^{\circ}$.

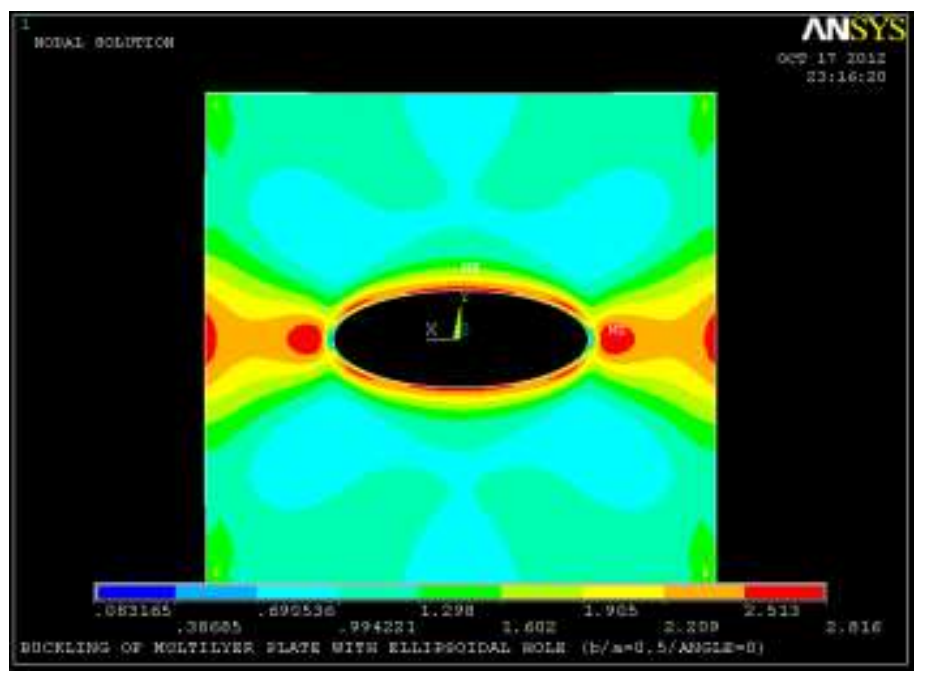

Fig. (9) ANSYS contour Plot of Stress distribution for multilayer plate For $\theta=0^{\circ}$.

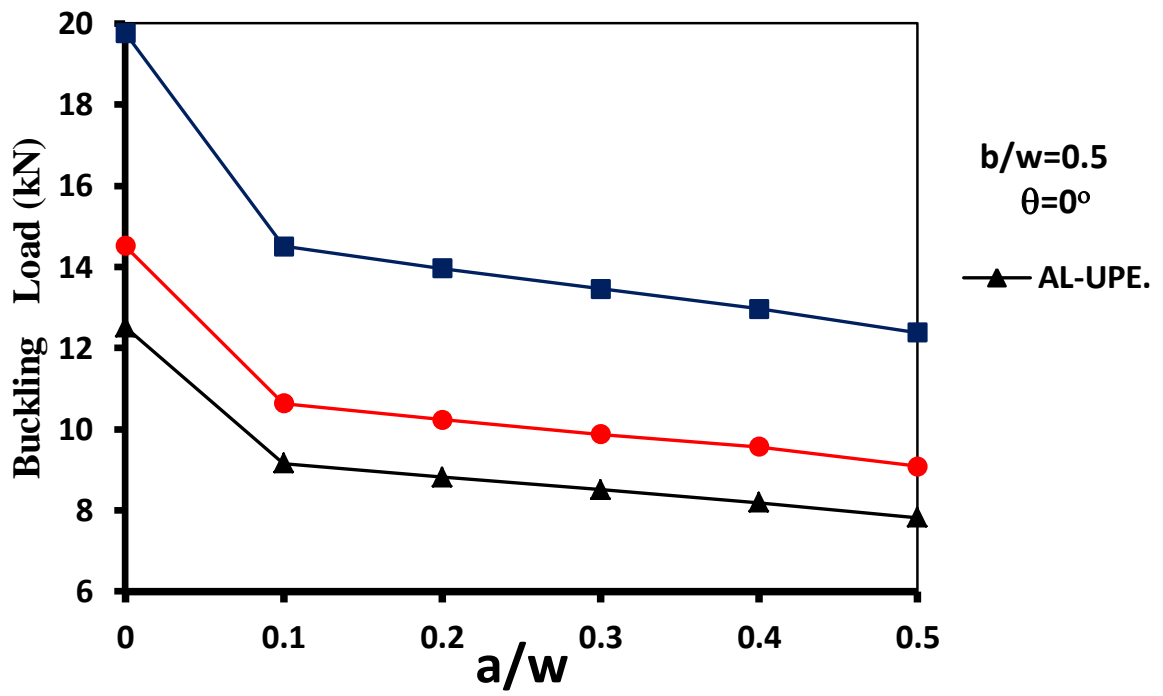

Fig. (10) Variation of buckling load with $(\mathrm{a} / \mathrm{w})$ ratios for $\theta=0^{\circ}$. 


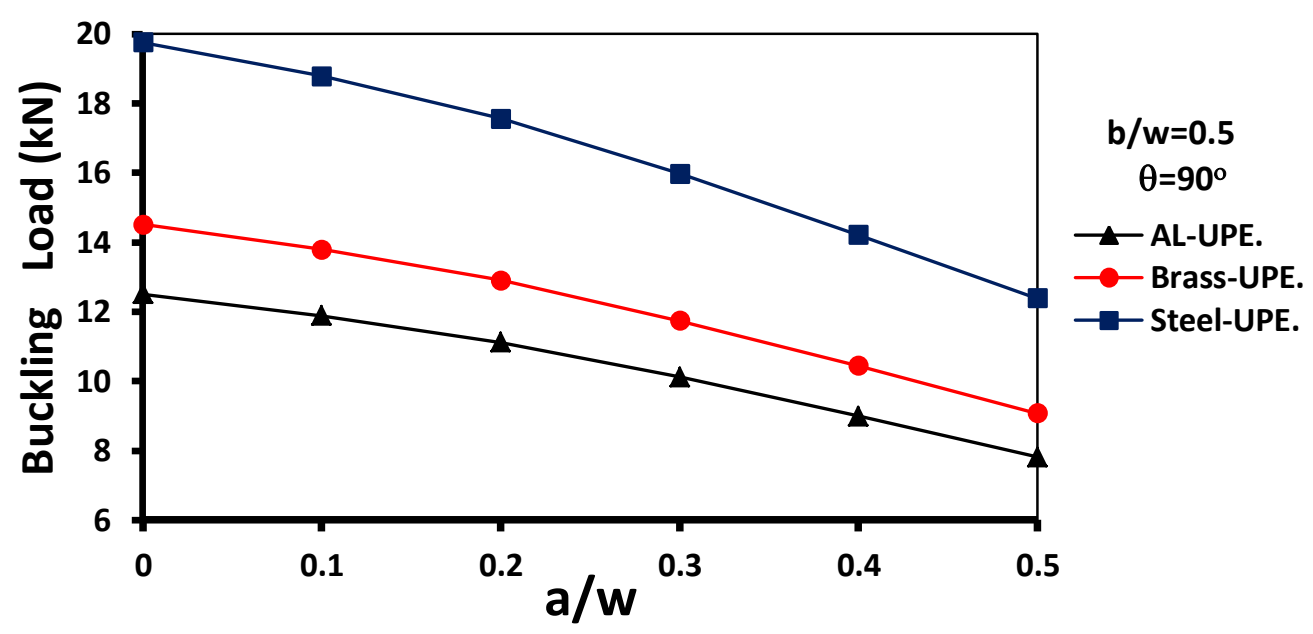

Fig. (11) Variation of buckling load with $(\mathrm{a} / \mathrm{w})$ ratios for $\theta=90^{\circ}$.

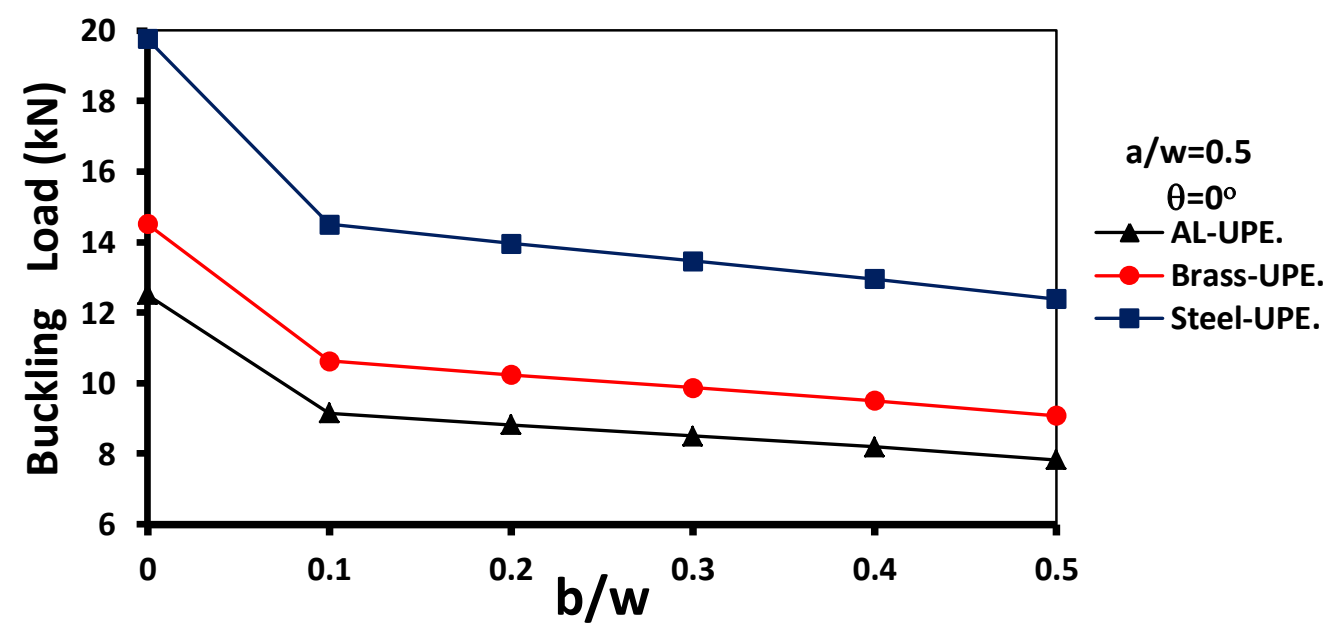

Fig. (12) Variation of buckling load with (b/w) ratios for $\theta=0^{\circ}$.

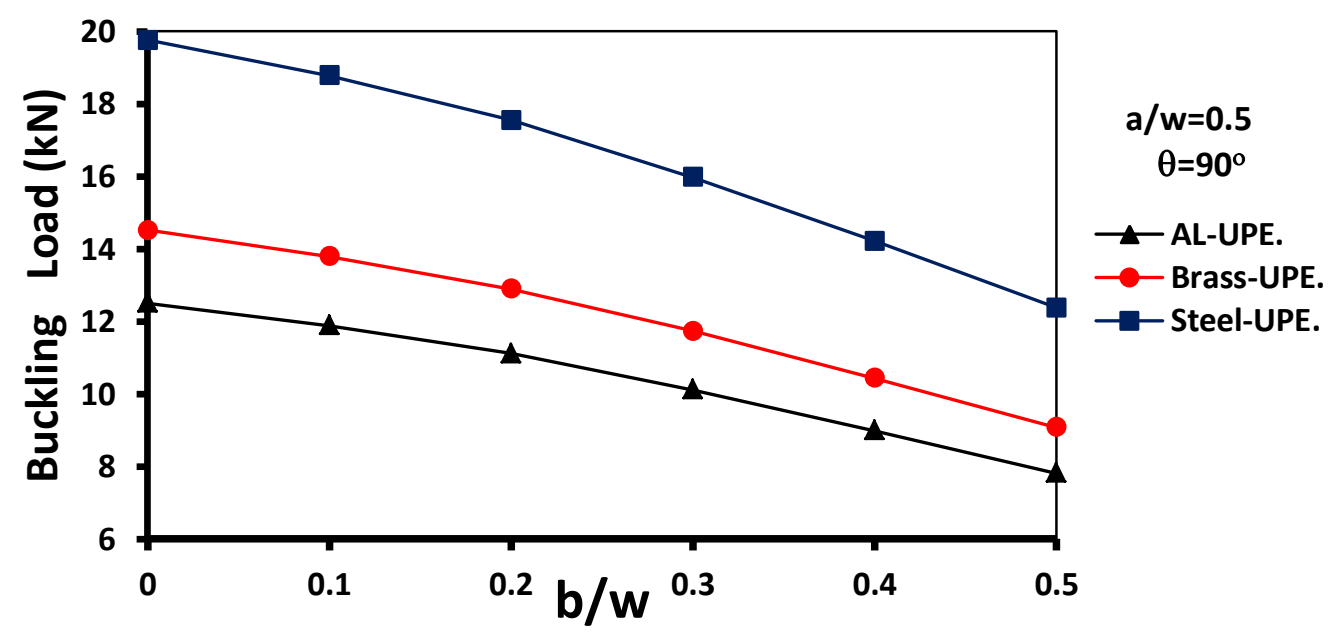

Fig. (13) Variation of buckling load with (b/w) ratios for $\theta=90^{\circ}$. 


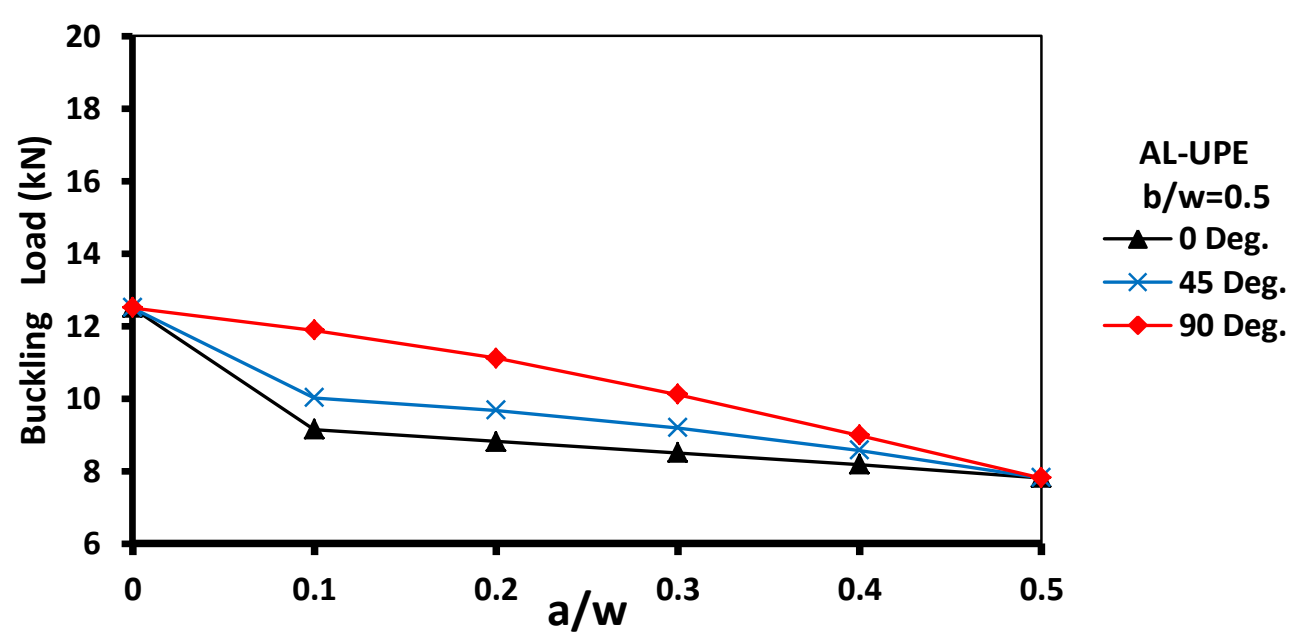

Fig. (14) Variation of buckling load with (a/w) ratios for AL-UPE.

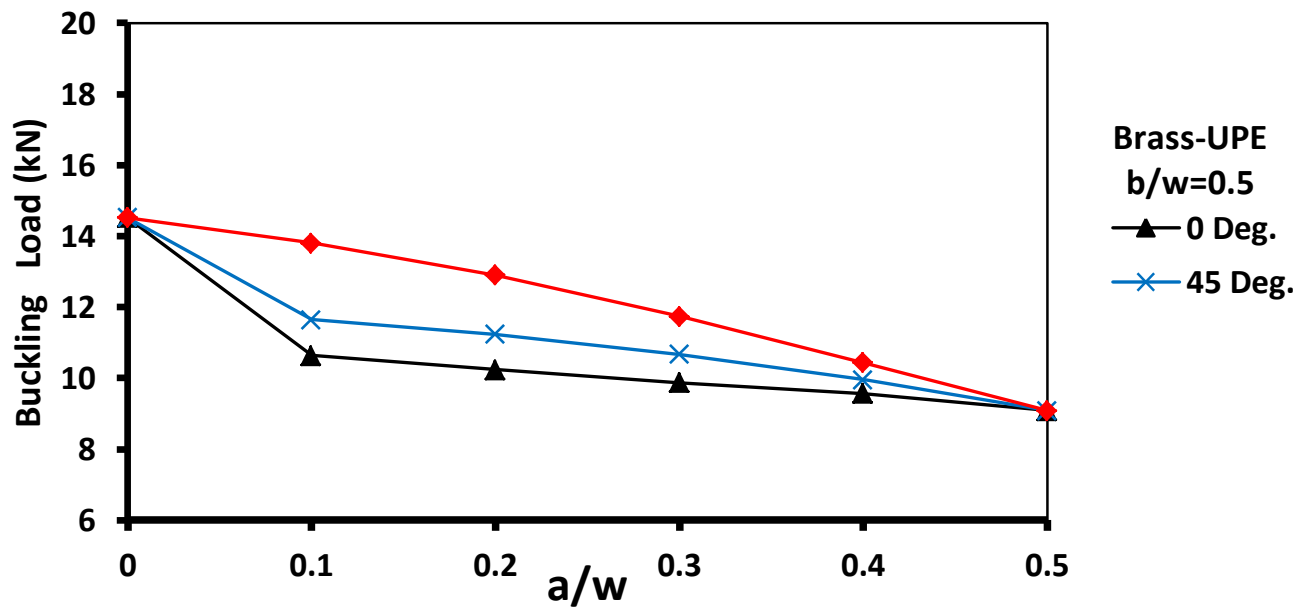

Fig. (15) Variation of buckling load with (a/w) ratios for Brass-UPE.

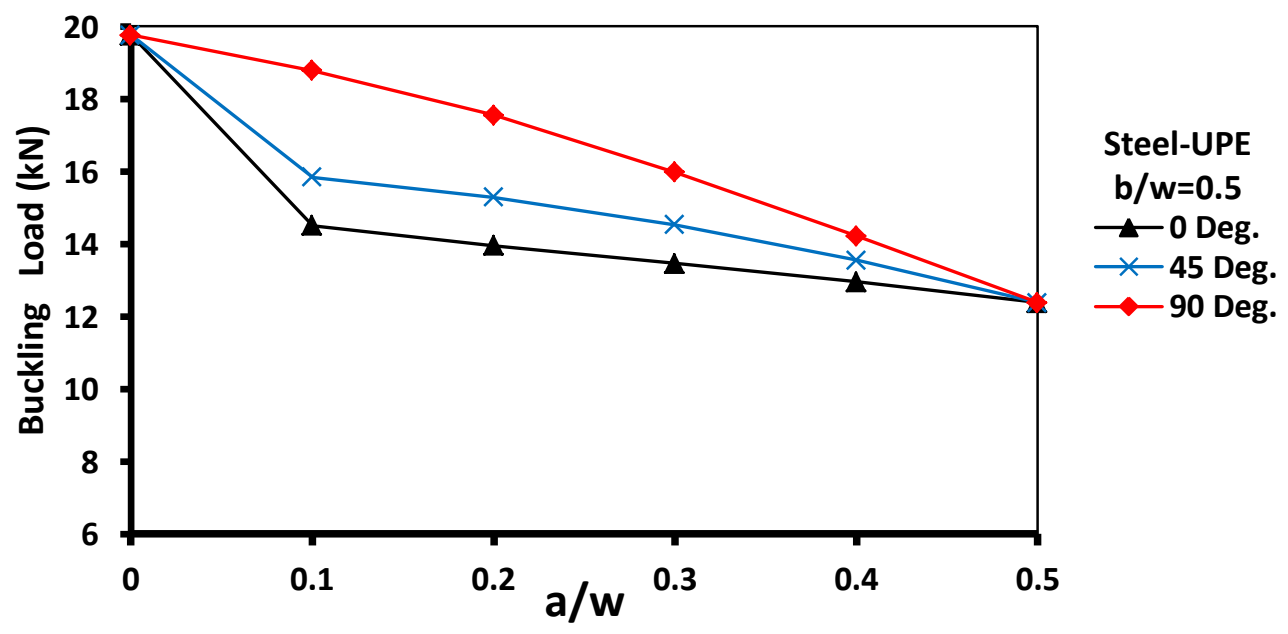

Fig. (16) Variation of buckling load with $(\mathrm{a} / \mathrm{w})$ ratios for Steel-UPE. 


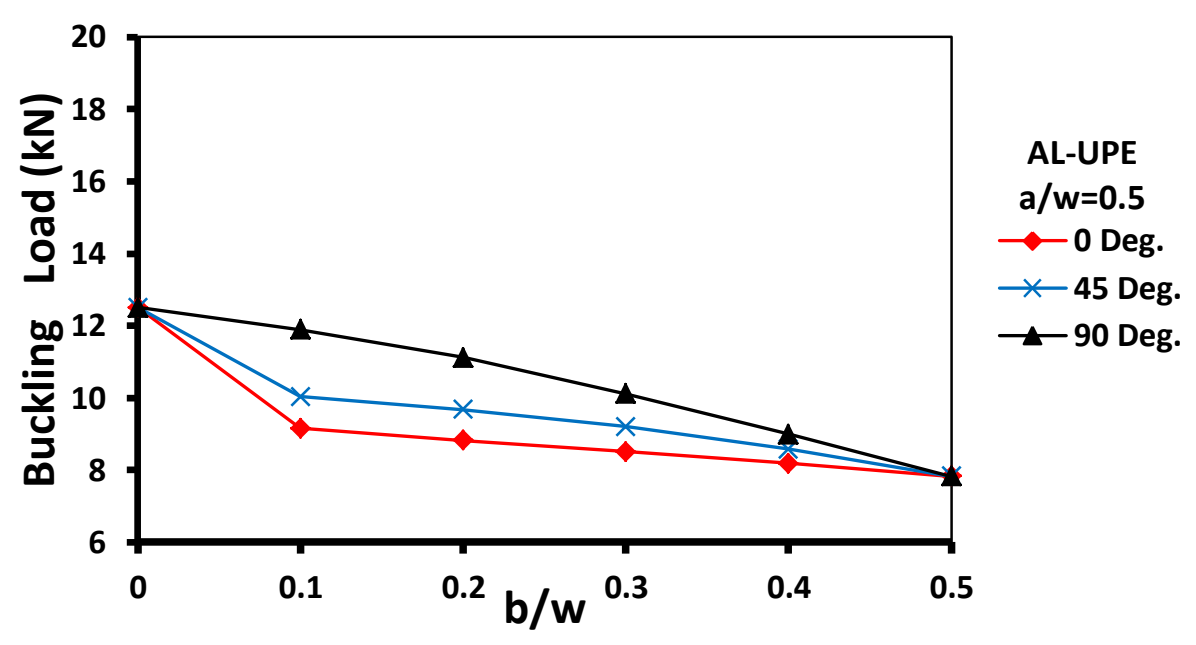

Fig. (17) Variation of buckling load with (b/w) ratios for AL-UPE.

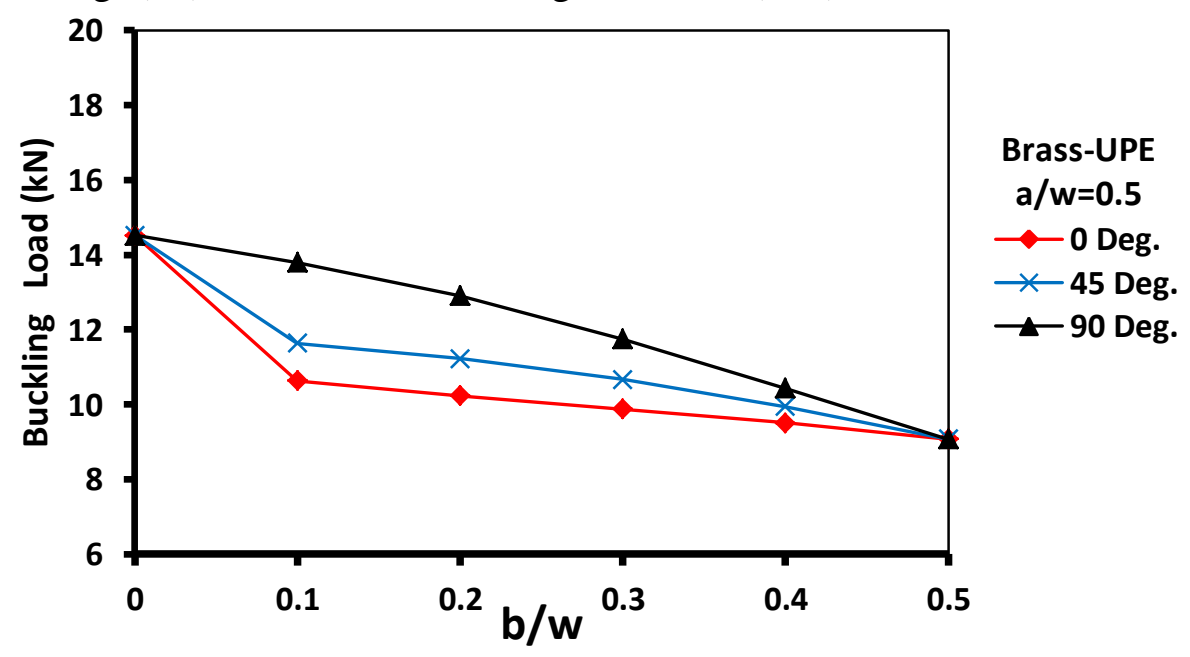

Fig. (18) Variation of buckling load with (b/w) ratios for Brass-UPE.

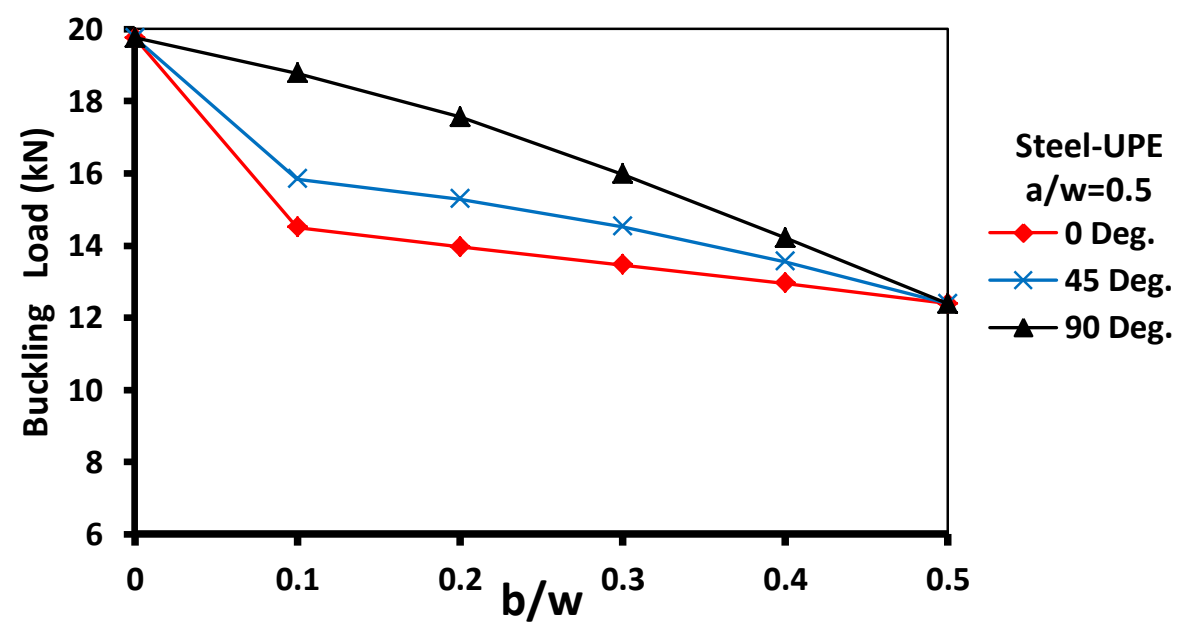

Fig. (19) Variation of buckling load with (b/w) ratios for Steel-UPE. 


\section{Conclusions}

(1)-The mild steel -UPE multilayer plate with central cut out is stronger than brass -UPE multilayer plate and aluminum -UPE multilayer plate .

(2)- The magnitude of buckling load were decreased significantly by increasing $(\mathrm{a} / \mathrm{w})$ and (b/w) ratios.

(3)- the presence of cutouts reduces the buckling load due to stress concentration and material removal effects.

(4)-Values of the major diameter at angle $\theta=90^{\circ}$ give the higher critical buckling load .

\section{Future work}

1- Study the buckling analysis of composite plates with central cut outs experimentally and comparing it with the available theoretical work.

2- Study the effect of pure shear loading condition on the shear buckling strength of composite plates.

\section{References}

1- Aydin M. komur et al," Buckling analysis of laminated Composite Plates with an elliptical / circular cutout using FEM" Journal of Advances in Engineering Software Vol. 41, 2010, pp.161-164.

2-Gansen.C, Dash P.K. ,'Elasto Buckling Behavior of Gfrp Laminated Plate With Central Holes" International Journal of Mechanical \& Industrial EngineeringVol.1, issue-1, 2011, pp.73-76.

3- Niranjan M. S. et al,"Static analysis of thick skew laminated composite plate with elliptical cutout" Central Holes" Indian Journal of Engineering \& material sciences Vol.16, 2009, pp.37-43 February.

4- Rajendran S., Song D.Q. "Finite element Modeling of Delamination Buckling of Composite Panel Using ANSYS" Proceeding of $2^{\text {nd }}$ Asian ANSYS user Conference, Nov 11-13, (1998), Singapore.

5- Niranjan M. S. et al "Effect Of Ellipse orientation on the Thermoelastic behavior of skew laminated composite plate with elliptical cutout" Bull. Mater. Sci. Vol.32, No. 1, February 2009, pp.59-64.

6- Husam Al Qablan, et al, "Assessment of buckling Behavior of Square Composite Plates with Circular Cutout subjected to in-Plane Shear", Jordan Journal of Civil Engineering, Vol.3, No. 2, 2009, pp.184-195.

7-Firas S. Jarrar, Naser S. Al-Huniti," Buckling Behavior of laminated Metal-Matrix Composite Plates With Cutouts" The $6^{\text {th }}$ Jordanian International Mechanical Engineering Conference (JIMEC'6),22-24 October (2007),Amman-Jordan.

8- Hani Aziz Ameen "Buckling Analysis of Composite Laminated Plate with Cutouts”, Eng. \& Tech. Journal, Vol.1, No. 8, 2009 ,pp.1611-1621 .

9- Raed Hekmat Maty," Buckling Behavior of Aluminum plate with different shapes of central cutouts" Thesis, August 2011,.Mosul University.

10- Anas Obeid Al-shimmery "Study of Factors Affecting the Determination of Forming Limit Diagrams for Sheet Metals",M.Sc. Thesis Applied Mechanics and Production, 2005 ,University of Mosul.

11- Hana A. Sumaig, "Effect of Reinforced by Zinc Oxide Powder on the Mechanical Journal, Vol.29, No. 10, 2011, pp.474-484.

12- Hiba J. Jaafer," Effects of Fibers on Damping Behaviors OF Composites Materials" Thesis, 2010, University of Technology.

13- ANSYS 9 program, "Theory, Analysis and Element Manuals", 2006.

14- David W. A. Rees, "Mechanics of Optimal Structural Design: Minimum Weight Structures “, John Wiley \& Sons, 2009, pp.526-535. 